УДК 821.161.1(091)

ББК 83.3(4Рос)

\section{5. Заславский}

\section{"ДАРЫ ТЕРЕКА" \\ М. Ю. ЛЕРМОНТОВА: \\ ПРОТИВОРЕЧИЯ \\ КАК СТРУКТУРНАЯ \\ ОСНОВА МИРА}

Предложен анализ «Даров Терека» как целостного произведения. Проведено структурное сравнение историй с тремя дарами Терека. Инвариантом произведения оказывается двойная структура, в которой совмещаются противоположности (верх низ, умирание - возрождение). В звуковой структуре значимы анаграмматические построения - такие, что сочетание «дар» как бы переносится самой рекой. Обсуждаются параллели c «Зимним вечером» Пушкина. Финальный эпизод включает «Дары Терека» в ряд произведений Лермонтова о любви, простирающейся за пределы жизни, куда в частности относятся также «Любовь мертвеца», «Демон» и «Штосс».

Ключевые слова: мотив; двойная структура; анаграмма; художественное пространство; художественное время; структурные противоречия; оппозииия верх - низ.

DOI 10.18522/1995-0640-2020-3-120-129

Заславский Олег Борисович - докт. физ.мат. наук, ведущий научный сотрудник Харьковского национального университета им. В.Н. Каразина

E-mail: zaslav@ukr.net

(C) Заславский О.Б., 2020.

\section{Введение}

Литература, посвященная данному произведению Лермонтова, сравнительно невелика достаточно посмотреть сведения на этот счет в Лермонтовской энциклопедии. С тех пор, насколько нам известно, список соответствующих публикаций расширился незначительно. Причем написанное о «Дарах Терека» в основном представляет собой беглые упоминания о стихотворении (в основном, о его связи с фольклором); работы, специально ему посвященные, практически отсутствуют. В данной работе мы делаем попытку заполнить этот пробел и предлагаем целостный анализ структуры произведения.

\section{Три истории}

В сюжете стихотворения три истории, связанные с тремя подарками Терека Каспию. Здесь возникает ключевой вопрос, который в работах о нем, как правило, не замечается или обходится. Есть ли связь между ними, и в чем она состоит? Как адекватно описать различия? Мы полагаем, что между всеми тремя историями есть структурное соответствие. И состоит оно в том, что эти истории и их герои различаются по уровню субъектности. Причем мерой этой субъектности служит нарушение / следование нормам.

Валуны, «пригнанные» Тереком, обладают, очевидно, нулевой степенью субъектности, соответственно в их отношении употреблено слово «стадо» - набор элементов, которые друг от друга ничем существенным не отличаются. Этот подарок не вызывает интере- 
са у Каспия. Следующий подарок - погибший кабардинец. Это - воин, верный своему долгу. Он следует нормам своей культуры - неслучайно упоминается стих из Корана, записанный на его налокотниках. Но этот герой представляет собой элемент предсказуемой и отлаженной военной системы, никак не выделяясь среди других потенциально достойных соплеменников. И этот подарок оставляет Каспий равнодушным.

Рассмотрим теперь третий подарок. Прямо это не сказано, но представляется достаточно очевидным, что «казачина гребенской» убил казачку за измену로. В пользу этого говорит и ее посмертная судьба, которая согласуется с такой реконструкцией и отчасти повторяет ключевой момент жизни казачки: она меняет того, кому принадлежит, переходя от Терека к Каспию. В истории с казачкой и «казачиной» присутствует двойное нарушение - вероятная измена казачки и преступление, которое последовало в ответ ${ }^{2}$. Оно выделяет «казачину» из коллектива: «Лишь один во всей станице».

Теперь обратим внимание на Каспий. Спокойное море, он вдруг становится «как гроза», у него загораются глаза от страсти, причем подчеркнуто, что это - старец. То есть и здесь нарушаются привычные нормы.

Соответственно с характером историй, меняется и степень подробности их изложения. О валунах, почти не отличимых друг от друга, говорится предельно кратко, вскользь - «И валунов им, на славу, Стадо целое, пригнал». О кабардинце сообщается существенно больше, однако отсутствует его индивидуальная история. Это - один из многих воинов со сходной судьбой. Больше всего сказано про казачку. Там - нестандартная история, излагающая эксцесс, исключение и преступление.

Во всех трех случаях нет случайных жертв - все жертвы получаются в результате целенаправленного насилия. Терек разоряет «родной» Дарьял и именно так пригоняет «стадо» валунов. Враги убивают кабардинца на поле битвы. «Казачина» убивает свою возлюбленную.

Все это проливает определенный свет на выбор Каспия - почему он, отвергнув два первых подарка, принял третий. Разумеется, главной мотивировкой здесь оказывается «страсть» Каспия к погибшей девушке. Однако, как представляется, этого недостаточно. Ведь иначе вся история о ней, рассказанная Тереком, оказалась бы излишней, - Каспий и так принял бы ее. В финальном эпизоде повышенную степень субъектности проявляет и сам Каспий: «старец», в противоречии с таким называнием, неожиданно встает перед мертвой красавицей. Так что именно повышенная субъектность, поведение, противоречащее стандартным нормам, имеет в «Дарах Терека» шансы на реализацию. Принимая волны с мертвой казачкой, переживающий приступ страсти старый Каспий как бы достраивает характерную для мира стихотворения картину, в которой доминируют аномалии.

Но дело оказывается не только в максимально возможном своеволии и нарушении сложившихся норм, но и в том, что (как будет ясно ниже) актуальные аномалии противоречат не только нормам, но и друг 
другу. Прежде всего, это проявляет себя в организации художественного пространства, к анализу которого мы переходим.

\section{Художественное пространство: роль вертикали}

Терек течет, разумеется, сверху вниз. Это само по себе очевидное обстоятельство деавтоматизуется явным упоминанием, что он рожден высоко в горах и вскормлен облаками. В начальной, бурной фазе Терек течет с резким перепадом высот. Затем он попадает в зону степей, где рельеф становится более пологим. Там Терек говорит, что хочет отдохнуть. Однако именно 3-я история, относящаяся к зоне плавного течения и связанная с самым ценным подарком, характеризуется тем, что ее участники идут наперекор силе тяжести. Молодой «казачина», убив возлюбленную, ищет смерти в горах, т.е. ему еще нужно подняться наверх. Мертвая казачка вдруг всплывает снизу вверх. И сам Каспий встает снизу вверх. Причем он сравнивается с грозой, но гроза - это событие в зоне верха.

Если сопоставить все три «подарка», то они оказываются распределены по вертикали: тяжелые валуны оказываются внизу, кабардинец (который находится в воде, но не всплывает) - где-то посередине, казачка - наверху.

Получается, что мир гибели и смерти неоднороден, и в нем оказывается возможным «возрождение». Соответствующий статус получает в нем тот, кто либо сам поднимается навстречу своей гибели и принимает достойную смерть в бою («казачина гребенской»), либо становится объектом перемещения снизу вверх (мертвая казачка). Это достигается перемещением вертикально вверх, против природной силы тяжести.

Противопоставление верха и низа проявляет себя не только в наличии бурной фазы, где существует природный перепад высот, и где Терек «воет, дик и злобен». Оно значимо и в плавной фазе, где Терек растекается по степи, причем здесь перемещение вдоль вертикали встречается дважды. Селение, из которого происходит убитая казачка, находится «над рекой» - соответственно, ее тело попадает в Терек сверху вниз. Но на это событие убийца, ищущий после совершенного им убийства смерти самому себе, реагирует перемещением снизу вверх: он направляется в горы, где и ждет его верная смерть. И убийство казачки и воздаяние за него оказываются связанными с движением вдоль вертикали в противоположных направлениях.

\section{Динамика поэтического мира}

В мире стихотворения постоянно что-то происходит, но вслед за изменениями следуют прямо противоположные процессы. Убыль энергии, вплоть до смерти, сопровождающаяся опусканием вниз, компенсируется ее восстановлением и выбросом вверх. Мертвая казачка падает в воду, но потом, уже в мире смерти, она как бы получает своеобразную компенсацию, всплывая вверх по воле Терека. Река теряет напор при движении сверху вниз вплоть до точки, где она должна войти в состав моря и стать 
неотличимой от него. Но при этом само море, куда она так стремится, совершает неожиданный бросок вверх. Сюжет развивается таким образом, что как будто существует «разность потенциалов» между верхом и низом, которая никуда не девается, подчиняясь своего рода закону сохранения. Происходящее в мире стихотворения оказывается несколько неожиданным подтверждением общего принципа, сформулированного, Ю. М. Лотманом: «любая идея получала в сознании Лермонтова значение только в том случае, если она, во-первых, могла быть доведена до экстремального выражения и, во-вторых, если на другом полюсе лермонтовской картины мира ей соответствовала противоположная, несовместимая и непримиримая с ней структурная экстрема» [Лотман, 1988, c. 231].

Из представленных закономерностей в произведении есть одно кажущееся исключение, но оно лишь подтверждает правило. Мертвый кабардинец не всплывает, но и не тонет, о его дальнейшей судьбе ничего не говорится. Поскольку нет «минуса» в перемещении, то отсутствует и плюс. Судьба мертвого кабардинца остается неясной. Можно предположить, что он будет вечно ожидать в промежуточном положении. В пользу этого говорят следующие детали. У самого Лермонтов есть схожий образ: мертвый витязь, который лежит на дне реки («Русалка», 1832). Здесь проявило себя общее свойство поэтики Лермонтова. В ней существуют процессы, которые никогда не заканчиваются, но их участники никогда не сдаются и/или не пропадают [Заславский, 2016]. В данном случае назван «Взор открытый, безответный», причем в применении к уже мертвому кабардинцу - соответственно, надо полагать, что в мире смерти он будет вечно всматриваться в ничто в тщетной попытке увидеть врага и дождаться его реакции.

Заметим еще, что противоречие, связанное с тем, что «старец море» воспламеняется от вида молодой казачки, подчеркнуто звукописью: старец - страсть. Такой эпизод имеет аналог и в других произведениях Лермонтова. Сюда можно отнести «Смотрите, как летит, отвагою пылая...», где говорится об обманчивости седины, которая сравнивается со струей кипучего вина в старой бутылке. Об омоложении в результате эротических впечатлений говорится и в стихотворении «Это случилось в последние годы могучего Рима»: «Дряхлые стариь, любуясь на белье плечи, волнистые кудри, На темнье очи ее, молодели».

\section{Художественное время: жизнь, смерть и река}

Мир стихотворения структурирован не только в пространстве, но и во времени, в том числе физическое течение Терека может быть сопоставлено с течением человеческой жизни. В 1-й строфе упоминаются плач и слезы Терека. Каково их происхождение? Мы полагаем, что они там появляются потому, что в 1-й строфе, где описывается Терек в своей начальной фазе, он является ребенком. Действительно, по свидетельству самого Терека в следующей строфе, он «родился у Казбека, Вскормлен грудъю облаков» - речь идет о ранней фазе жизни. В результате первые 
четыре строки порождают параллель с пушкинским стихотворением «Зимний вечер», где говорится про бурю «Tо, как зверь, она завоет, To заплачет, как дитя». Однако есть и существенное различие. У Пушкина буря - это исходный объект, с ребенком она лишь метафорически сравнивается. У Лермонтова Терек и есть ребенок в смысле возраста (в 1-й строфе), так что оба объекта совмещены ${ }^{3}$; буря же оказывается лишь объектом сравнения ( «Буре плач его подобен»).

Река - традиционный элемент в мифопоэтической картине мира, отделяющий «тот» мир, царство смерти от мира жизни. Однако в лермонтовском стихотворении река отнюдь не разделяет собой зоны жизни и смерти в поперечном по отношению к ней направлении (как это было бы в традиционном случае): здесь течение жизни/смерти совершается в продольном направлении, вдоль самой реки. Динамика жизни и смерти, связанная с рекой, осуществляется не по отношению к внешнему миру, а по отношению к ней же. По мере развертывания сюжета Терек проходит разные фазы жизни и одновременно - разные пространственные фазы. Он пережил свой бурный период и хочет успокоиться. Разговор Терека с Каспием представляет собой просьбу о возможности поменять собственную идентичность умереть как река, но стать частью моря.

Что же касается мира человеческого, то по отношению к нему Терек оказывается переносчиком смерти - он несет мертвые тела умерших насильственной смертью. Течение воды как носителя смерти дважды дублируется в образе струи. Это струйка крови, обагрившая края усов мертвого кабардинца, а также струйка крови у мертвой казачки. Это аналог самой реки, - жидкость, уносящая жизнь. Ровно и слабо текущая (без неожиданных вспышек активности, как у Каспия) жидкость связана со смертью, и только.

Отметим ряд значимых противоречий. Терек говорит о своей прошлой энергии и вовлеченность в дела людские: «С чуждой властью человека // Вечно спорить был готов». Речь идет о вечности. Однако о ней говорится в прошлом времени - так, как будто эта вечность уже кончилась. Противоречие можно разрешить, если учесть, что процесс течения реки является одновременно динамическим и стационарным. Одни частицы воды уходят и совершают тот путь, который описан в тексте, другие приходят им на замену. (Подобным же образом следует интерпретировать слова о «гладком источнике» в «Тамани» [Заславский, 2008, с. 71 - 72].) Соответственно, в фазе молодого Терека спор с властью человека продолжается до сих пор. На локальную историю с определенным концом накладывается ее бесконечное повторение. Река как динамическое явление не умирает (приходят новые частицы воды), но как раз данный ее «экземпляр», о котором рассказано в стихотворении (и который включает в себя историю с казачкой и кабардинцем) заканчивает свое существование.

\section{Звукопись: перемещение ключевых слов в тексте}

Движение реки не только переносит частицы воды - в некотором смысле оно переносит и отдельные слова, на чем мы сейчас остановим- 
ся. Ранее в литературе уже высказывалось соображение, что «само движение Терека от истоков до устья, от верховьев Казбека (...) может быть метафорически уподоблено поэтапному процессу текстопорождения» [Поплавская, 2007, с. 6]. Однако это утверждение в указанной работе обосновано не было. Мы полагаем, что описания течения реки в стихотворении еще недостаточно для такой параллели - здесь требуется нечто большее. И дело здесь не в «самом движении Терека», а, как сейчас увидим, в наличии дополнительной структуры, связанной со звукописью, что действительно позволяет придать смысл (причем отнюдь не метафорический) параллели между развертыванием текста и течением реки.

О наличии звукописи в этом стихотворении уже писали. Так, в статье в Лермонтовской энциклопедии отмечаются «аллитерации («разорил родной Дарьял»), с необычайной щедростью рассыпанные по всей балладе, придающие особую энергию и без того энергичному ритму 4-стопного хорея» [Аринштейн, 1981, с. 126]. Но такой подход рассматривает звукопись просто как физический орнаментальный эффект. Однако дело не только в том, что придается «энергия», но и в прямой связи ключевых образов между собой. Такие связи захватывают не только стоящие рядом слова (чем и создается тот эффект, о котором написано в Лермонтовской энциклопедии), но и разделенные значительными расстояниями в тексте. Первые ДАРы Терек приносит из ДАРьяла. Далее в качестве такого дара оказывается - кабАРДинец. Убийца казачки (которая стала главным подарком Терека) «Не тоскует нАД Рекой». В результате соответствующий звукосмысловой лейтмотив анаграмматически проходит через все произведение, так что ключевое слово «дар» несколько раз «всплывает» в толще текста. В этом смысле слова как бы повторяют физические перемещения Терека, его волн и всех трех его «даров».

Кроме того, звукосмысловой эффект присутствует даже и в том случае, когда некоторые из слов не называются явно (но подразумеваются): сыны Каспия - это его ВАЛы и ВоЛНы, которым Терек прислал ВАЛуны «на сЛАВУ». Также, звуковое соответствие связывает сами имена главных героев: ТеРеК и сТаРиК Каспий. Оно создает фон, на котором острее выделяется их противопоставление; с другой стороны, близкий звуковой состав отражает тот факт, что Терек вольется в Каспий и станет от него неотличим.

\section{Двоемирие, любовь и смерть}

В произведении переплетаются мотивы любви, борьбы и смерти. Это переплетение, несмотря на его кажущуюся простоту, оказывается весьма нетривиальным. Соответственно, попытки его проанализировать, исходя из предвзятых шаблонных представлений и в отрыве от структуры как целого, ведут к искажению смысла или малосодержательным банальностям.

Б. Эйхенбаум писал, что «Терек, обращаясь к Каспию, говорит о своей вечной борьбе с “чуждой властью человека", и восторг, с которым Каспий принимает в свои объятия труп убитой казачки, кажется проявле- 
нием той же борьбы» [Эйхенбаум, 1961, с. 113]. Такая интерпретация не согласуется с текстом. Ведь если бы дело заключалось в этом, то у Каспия было бы куда больше «оснований» принять к себе не казачку, а тело убитого воина; непонятно, в чем может состоять «борьба» с мертвой казачкой. Кроме того, Терек вообще не имеет отношения к убийствам носителей «чуждой власти»: он лишь доставляет мертвые тела, убитые другими людьми - кабардинца, павшего на поле битвы, и казачки, убитой влюбленным в нее казаком. Также ясно, что казачка для Каспия важна именно как объект любви (недаром упоминается страсть в его глазах), а вовсе не как представитель враждебной человеческой силы. Скорее дело обстоит наоборот - это люди оказываются во власти Терека, но после смерти.

Была попытка [Ермоленко, 1966, с. 342] рассмотреть мотивы любви и смерти в аксиологическом духе, с подчеркиванием высшей ценности любви и ее противостоянию смерти: «Буйному» разгулу стихийных сил в природе и человеке, несущему с собой смерть, противостоит в балладе вечное животворящее начало - любовь, источник жизни, ее движения и обновления» [Ермоленко, 1966, с. 342]. Однако уже одно лишь то, что объектом любви является мертвая казачка, заставляет считать, что такие пассажи о «животворящем начале» оторваны от контекста и идейной проблематики стихотворения в целом.

Дуальное противопоставление действительно реализуется в произведении, однако в нем значима, прежде всего, сама сочетаемость несочетаемого, приводящая к неустранимо двойной структуре, которая простирается за границу жизни и смерти. Здесь проявляет себя вариант ситуации, которая по-видимому играет ключевую роль в поэтическом мире Лермонтова, составляя один из его инвариантных сюжетов. Он связан с любовью, направленной на объект, принадлежащий другому миру. Сюда, в частности, можно отнести «Любовь мертвеца» и «Демон», а также «Штосс» - произведение, к моменту создания «Даров Терека» еще не написанное, так что в данном отношении здесь можно видеть подступы к нему. А именно, в конце, когда казачка попадает к Каспию, получается своего рода любовь в мире смерти. И то, как старец принимает казачку, может быть сопоставлено с «Лесным царем» Гете - произведением, играющим ключевую роль в «Штоссе» [Заславский, 2013]. У Гете Лесной царь «принимает» ребенка. Но есть и существенное различие. В «Лесном царе» еще живой ребенок видит Лесного царя, но попадает туда только мертвым, тогда как в «Дарах Терека» казачка уже мертва к моменту, когда она оказывается перед входом в царство Каспия. Однако дальнейшее обсуждение таких сюжетов увело бы нас далеко за пределы нашей темы. Здесь требуется отдельное исследование.

\section{Структурный инвариант поэтического мира стихотворения}

Подведем итоги. Целью Терека в его разговоре с Каспием было найти приют для успокоения. Однако оказалось, что вместо затухания активности водной природы следует ее вспышка. При этом природа (Каспий) вовлекает в нее и человеческий мир, так что неожиданный импульс получает, уже в царстве смерти, и убитая ранее казачка. Но ее 
«возрождение» происходит в мире смерти, в котором она и остается. А поскольку такое «возрождение» оказывается ценой за возможность Тереку успокоиться (фактически умереть, влившись в воды Каспия), то в результате возникает ряд глубоких противоречий. С одной стороны, казачка перемещается вверх, к «жизни» внутри смерти. С другой стороны Терек, который это осуществляет, движется вниз, к потере своей идентичности и функциональной смерти. Но поскольку в результате Каспий принимает волны Терека, одновременно возрождаясь от страсти к мертвой казачке, то для Терека должна получиться смерть внутри жизни.

При этом возрождение Каспия сочетается с указанием в тексте на старость, которая не отменяется, но переходит в жизненно активную фазу. Получается, что более старый Каспий возрождается, а более молодой Терек проявляет признаки дряхлости, стремясь успокоиться и функционально умереть, став частью Каспия. (То, что Терек в этой паре - более молодой, следует хотя бы из того, что он называет Каспия «дядя», причем при описании этого обращения Каспий в тексте фигурирует как «старец»).

Миру стихотворения свойственна активность в двух аспектах. На уровне персонажей она проявляет себя в том, что выделяются персонажи с повышенной субъектностью (см. выше раздел «Три истории») именно с ними происходят реальные перемены, причем это относится как к человеческому, так и природному миру. И эти перемены приводят к построению новых конструкций, чья структура построена на противоречиях. Такая противоречивость и оказывается проявлением глубинных свойств поэтического мира стихотворения. Она является более фундаментальной, чем конкретное противоречие между человеческим и природным миром и даже между жизнью и смертью как таковыми, поскольку носит более абстрактный и общий характер. Переходя границу между жизнью и смертью, она оказывается общей и неустранимой чертой поэтического мира данного произведения, его структурным инвариантом.

\section{Заключение}

Стихотворение «Дары Терека» (1839) занимает пограничный характер в творчестве Лермонтова. Оно завершает и ярко воплощает ту фазу лермонтовского творчества, которая связана с противопоставлением непримиримых друг с другом структурных экстрем. Но на примере этого стихотворения видно, что даже в этой фазе дело не сводится к простым дуальным противопоставлениям, - в целом получается достаточно сложная и разветвленная картина. Вскоре в творчестве Лермонтова появится тенденция к гармонизации его поэтического мира [Лотман, 1988, с. 231 - 234], и ситуация усложнится еще больше.

Автор выражает благодарность Ю. П. Степановскому за полезные обсуждения.

\section{Примечания}

${ }^{1}$ Белинский видел здесь еще 2 варианта и упрекал Лермонтова за такую неопределенность. Помимо убийства из ревности Белинский рассматривал возможность, что казак еще не знает о смерти возлюбленной, или что ее убил 
чеченец, которому казак готовится отомстить [Белинский, 1954, с. 544]. Оба варианта искусственны и означали бы распад системных связей в тексте.

${ }^{2}$ Если же игнорировать напрашивающуюся здесь измену и считать, что это - убийство «просто» из ревности (как об этом писал Белинский - см. выше), то получается сумасбродный поступок, никак по смыслу не связанный с остальным текстом.

${ }^{3}$ В стихотворении присутствует и другая параллель с Пушкиным - с его стихотворением «Кавказ» [Коровин, 1973, с. 88].

\section{Литература и источники}

Аринштейн Л. М. (1981) «Дары Терека» // Лермонтовская энциклопедия. М.: Советская энциклопедия.

Белинский В. Г. (1954) Полн. собр. соч.: в 13 т. М.: Изд-во АН СССР, 1953 1959. Т. 4: Статьи и рецензии 1840 - 1841. 675 с.

Ермоленко С. И. (1996) Лирика М. Ю. Лермонтова: жанровые процессы / УрГПУ. Екатеринбург, б.и.,. 420 с.

Заславский О. Б. (2008) Герой, мир и структура текста: о «Тамани» М. Ю. Лермонтова // Wiener Slawistischer Almanach. Band 61. S. 69 - 83.

Заславский О. Б. (2013) Повесть Лермонтова «Штосс»: идейная структура и сюжет // Изв. РАН. Серия литературы и языка. Т. 72. № 4. С. 27 - 39.

Заславский О.Б. (2016) Парадоксы вечности в поэтике Лермонтова // Изв. РАН. Серия литературы и языка. Т. 75. № 1. С. 5 - 16.

Коровин В. И. (1973) Творческий путь Лермонтова. М.: Просвещение. 292 с.

Лотман Ю. М. (1988) В школе поэтического слова. Пушкин. Лермонтов. Гоголь. М.: Просвещение. 352 с.

Поплавская И. (2007) Взаимодействие поэтического и прозаического начал в сборнике «Стихотворения М. Лермонтова» (1840) // Вестн. Томского гос. ун-та. № 297.

Эйхенбаум Б. М. (1961) Литературная позиция Лермонтова // Эйхенбаум Б. M. Статьи о Лермонтове. М.; Л.: Изд-во АН СССР. 372 с.

\section{References}

Arinstein L. M. (1981) «Gifts Of The Terek». Lermontov encyclopedia. (In Russian).

Belinsky V. G. (1954) Complete works in 13 volumes, 1953-1959. Vol. 4. Articles and Reviews 1840-1841.675 p. (In Russian).

Eichenbaum B. M. (1961) Lermontov's Literary position. B. M. Eichenbaum. Articles about Lermontov. M.; L., Publishing house of the USSR Academy of Sciences. 372 p. (In Russian). Russian).

Korovin V.I. (1973) Lermontov's creative path. M., Prosveshchenie. 292 p. (In

Lotman Yu. M. (1988) In the school of the poetic word. Pushkin. Lermontov. Gogol. Moscow: Prosveshchenie. 352 p. (In Russian).

Poplavskaya I. (2007) Interaction of poetic and prose beginnings in the collection «Poems of M. Lermontov» (1840). Bulletin of the Tomsk state University's. № 297. (In Russian).

Yermolenko S. I. (1996) The Lyrics of M. Yu. Lermontov: genre and processes. UrSPU. Yekaterinburg. (In Russian).

Zaslavsky O. B. (2008) Hero, world and structure of the text: about «Taman'» M. Y. Lermontov. Wiener Slawistischer Almanach. Band 61. S. 69 - 83. (In Russian). 
Zaslavsky O. B. (2013) The Story of Lermontov, «Stoss»: the ideological structure and plot. Izvestiya Russian Academy of Sciences. Literature and language series, vol. 72, no. 4, pp. 27-39. (In Russian).

Zaslavsky O. B. (2016) Paradoxes of eternity in Lermontov's poetics. Izvestiya Russian Academy of Sciences. Literature and language series, vol. 75, no. 1, pp. 5-16. (In Russian).

Oleg B. Zaslavsky (Kharkov, Ukraine)

M. Yu. Lermontov's «Terek gifts»: Contradictions as a Structural Basis of the World

It is given the analysis of «Terek's gifts» as an integral work. Structural comparison of stories with three gifts is carried out. It is pointed out the poem's invariant, it is the double structure in which opposites are combined (top - bottom, dying - rebirth). The correspondence is revealed between anagrammatic constructions and the river's flow. Parallels with Pushkin's «Winter evening» are found. The final episode includes «Terek's gifts» into a series of Lermontov's works about love extending across the border of life. It contains, in particular, also «Love of the dead», «Demon», «Stoss».

Key words: motive, double structure, anagram, artistic space, artistic time.

Oleg B. Zaslavsky - grand Ph.D. of Physical and Mathematical Sciences. Kharkov National University named after V.N. Karazin. E-mail: zaslav@ukr.net. 